\title{
Long-term outcomes of patients with 10 or more colorectal liver metastases
}

\begin{abstract}
M A Allard ${ }^{1}$, R Adam*,1, F Giuliante ${ }^{2}$, R Lapointe ${ }^{3}$, C Hubert $^{4}$, J N M ljzermans ${ }^{5}$, D F Mirza ${ }^{6}$, D Elias ${ }^{7}$,

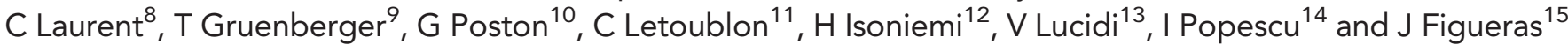

${ }^{1}$ Centre Hépato-biliaire, APHP Paul Brousse Hospital, Univ. Paris-Sud, INSERM U 935, Villejuif, France; ${ }^{2}$ Department of HBP Surgery, Catholic University of the Sacred Heart School of Medicine, Rome, Italy; ${ }^{3}$ Department of HBP Surgery, University of Montreal, Montreal, OC, Canada; ${ }^{4}$ Department of HBP Surgery, Cliniques Universitaires Saint-Luc, Université Catholique de Louvain, Louvain, Belgium; ${ }^{5}$ Department of HBP surgery, Erasmus University Medical Center, Rotterdam, The Netherlands; ${ }^{6}$ Department of HBP surgery, University Hospital Birmingham, Birmingham, UK; ${ }^{7}$ Department of Oncological Surgery, Gustave Roussy, Villejuif, France; ${ }^{8}$ Department of Surgery, Saint André Hospital, Bordeaux, France; ${ }^{9}$ Department of Surgery, Medical University of Vienna, Vienna, Austria; ${ }^{10}$ Department of Surgery, University Hospital Aintree, Liverpool, UK; ${ }^{11}$ Department of Surgery, University Joseph Fournier, Grenoble, France; ${ }^{12}$ Department of Liver Surgery and Transplantation, Helsinki University, Helsinki, Finland; ${ }^{13}$ Department of Surgery, Hospital Erasme, Université Libre de Bruxelles, Brussels, Belgium; ${ }^{14}$ Department of Surgery and Transplantation, Fundeni Clinical Institute, Bucharest, Romania and ${ }^{15}$ Department of Surgery, Dr Josep Trueta Hospital, Girona, Spain
\end{abstract}

Background: Although the number of colorectal liver metastases (CLM) is decreasingly considered as a contraindication to surgery, patients with $10 \mathrm{CLM}$ or more are often denied liver surgery. This study aimed to evaluate the outcome after liver surgery and to identify prognostic factors of survival in such patients.

Methods: The study population consisted of a multicentre cohort of patients with CLM ( $N=12406)$ operated on, with intention to resect, from January 2005-June 2013 and whose data were prospectively collected in the LiverMetSurvey registry.

Results: Overall, the group $\geqslant 10 \mathrm{CLM}(\mathrm{N}=529,4.3 \%)$ experienced a 5 -year overall survival (OS) of $30 \%$. A macroscopically complete (RO/R1) resection (72.8\% of patients) was associated with a 3 - and 5 -year OS of $61 \%$ and $39 \%$ vs $29 \%$ and $5 \%$ for R2/no resection patients $(P<0.0001)$. At multivariate analysis, RO/R1 resection emerged as the strongest favourable factor of OS (HR 0.35 (0.26-0.48)). Other independent favourable factors were as follows: maximal tumour size $<40 \mathrm{~mm}$ (HR $0.67(0.49-0.92))$; age $<60$ years (HR 0.66 (0.50-0.88)); preoperative MRI (HR 0.65 (0.47-0.89)); and adjuvant chemotherapy (HR 0.73 (0.55-0.98)). The model showed that 5 -year OS rates of $30 \%$ was possible provided RO/R1 resection associated with at least an additional favourable factor.

Conclusions: Liver resection might provide long-term survival in patients with $\geqslant 10$ CLM staged with preoperative MRI, provided R0/R1 resection followed by adjuvant therapy. A validation of these results in another cohort is needed.

In the past surgical series of colorectal liver metastases (CLM) published (Wilson and Adson, 1976; Ekberg et al, 1986) in the 1970s-1980s, the presence of more than three CLM was considered as a contraindication for resection. Since then, CLM management has considerably evolved (Adam et al, 2012). Innovations in surgical techniques have pushed the boundaries of resectability while the introduction of efficient cytotoxic agents in association with targeted therapies (Cutsem et al, 2009; Kabbinavar et al, 2009) have markedly increased tumour response rate and chance for surgery in patients with unresectable disease at presentation

*Correspondence: Professor R Adam; E-mail: rene.adam@aphp.fr

Received 25 November 2016; revised 25 April 2017; accepted 19 June 2017; published online 20 July 2017

(C) 2017 Cancer Research UK. All rights reserved 0007-0920/17 
(Adam et al, 2004a, 2009). As a consequence, the oncological dogma of 'no more than three CLM' has been progressively challenged. However, the cut-off number for which surgery does not provide any benefit is still unknown and there is currently very few data regarding the oncological results of liver resection performed in patients exhibiting a high number of CLM. We only found studies that focused on outcome of patients exhibiting more than four to eight CLM (Ferrero et al, 2004; Elias et al, 2005; Tamandl et al, 2007; Zakaria et al, 2007; Rees et al, 2008; Viganò et al, 2015) with too limited series to draw practical conclusions (Smith and McCall, 2009). As the majority of patients with a larger number of CLM are exclusively treated by chemotherapy, results of surgery are lacking.

On the other hand, chemotherapy has significantly increased its efficacy in recent years, but long-term survival still remains anecdotal (Van Cutsem et al, 2011; Cremolini et al, 2015).

This prompts us to investigate the outcome of patients operated on for a large number of CLM. As there is no established cut-off defining what a 'large' number of CLM is, we choose the cut-off of 10 CLM by analogy with the EORTC randomised trial in which 10 CLM was the limit for RFA indication. Beyond such cut-off, medical oncologists and surgeons usually consider that there is no more place for surgery.

The use of a large multicentric cohort of patients operated on for CLM allows us to obtain a critical number of patients operated on for 10 CLM or more, required to achieve this analysis.

Our objectives were the following ones: (i) to report the results of patients operated on for 10 CLM or more by comparing to that observed in patients with fewer CLM; and (ii) to identify within this group of patients, the factors associated with a real survival benefit.

\section{MATERIALS AND METHODS}

\section{Study population}

LiverMetSurvey registry. We used the multicentric cohort of patients operated on for CLM between January 2005 and June 2013, and whose data were prospectively registered in the LiverMetSurvey international registry. LiverMetSurvey (http:// www.livermetsurvey.org/) is an international database that prospectively collects clinical and pathological data of patients undergoing surgery for CLM (Adam et al, 2010; Andres et al, 2012; Viganò et al, 2012). This register currently involves 485 centres across a total of 59 countries. Data are prospectively entered by using an online questionnaire, which includes demographic and pathologic variables as well as informations concerning the type, duration and effects of preoperative treatment, the surgical procedure, the timing, location and treatment of recurrence, as well as the post-operative and longterm outcome. Data are regularly updated by each centre, and a quality control of the data is performed by a data manager who sends twice a year to each contributing centre a personalised information, concerning the items to complete or to update for each patient of the centre cohort.

Selection of the study population. Our initial study population consists of all consecutive patients registered in the LiverMetSurvey during the study period with available number of CLM on imaging studies at diagnosis (CT or MRI) of the liver disease. The resulting cohort consists on a total of 12406 patients. Of them, we specifically focused on patients exhibiting 10 CLM or more $(N=529)$.

All patients included in this study were operated on for CLM with an intention to resect on a curative intent. Some of them were not resected due to intraoperative discovery of extrahepatic disease or to more extended liver disease contraindicating radical surgery. In the remaining patients, resection was classified as R0, R1 or R2 as defined below.

Definition of the type of resection. R0 resection was defined by a macroscopically complete removal of the totality of hepatic metastases with $\geqslant 1 \mathrm{~mm}$-free margins. $\mathrm{R} 1$ resection referred to macroscopically complete removal of lesions with at least one positive margin $(<1 \mathrm{~mm})$ or the use of local ablation (radiofrequency and microwave ablation). R2 resection referred to a macroscopically incomplete resection.

Study design. This study was divided into three steps.

Step 1: comparisons of the group of patients with $\geqslant 10$ CLM with two other groups: 1-3 CLM and 4-9 CLM.

Step 2: identification of the factors affecting overall survival (OS) in the group $\geqslant 10$ CLM.

Step 3: calculation of survival probabilities in patients with $\geqslant 10$ CLM according to a predictive model.

\section{Statistical analysis}

Comparisons. Comparisons between categorical data and continuous data were done by using the $\chi^{2}$-test and ANOVA test, respectively.

Survival analysis. Continuous variables were transformed into categorical data by using the roughly rounded values of the mean as cut-off for more readability. The survival probabilities were calculated according to Kaplan-Meier method and survival plots were compared with the log rank test. For OS, time was calculated from the date of CLM diagnosis to the date of last news. For 'primary' DFS, time was calculated from the time of resection to the date of first relapse or death. Incomplete resection was considered as a relapse at time 0 . In case of multistep procedures (i.e., two-stage hepatic resection), the DFS was calculated from the date of last resection. 'Secondary' DFS was calculated for patients who underwent R0/R1 liver resection. Time for secondary DFS was the period between the first hepatectomy and the date of the last relapse that could not be treated curative intent. Relapse was defined as the occurrence of new metastatic localisation.

Multiple imputations. To avoid biased estimates (Janssen et al, 2010), missing data were imputed $(N=10)$. Variables with a proportion of missing values $>30 \%$ were not selected for imputation and not considered for analysis. Imputations were generated by using the predictive mean-matching method. Then, the plausibility of imputed data was checked.

Cox proportional hazards model. Variables with $P$-values $<0.15$ at univariate analysis were entered into a Cox proportional hazard model for multivariate analysis. Continuous variables were transformed into binary variables by using their mean value. This makes scoring system easier to use. The final selection of variables retained in the final model used the minimal Akaike Information Criterion approach. The proportional hazards assumption for each covariate and for the entire model was checked by using Schoenfeld's residuals.

Then, the coefficients obtained for each data set were combined to estimate the final regression coefficient according to Rubin's rule. (Rubin, 1987).

Prediction of survival probabilities. For each data set, we calculated the survival probabilities predicted by the final Cox model according to the different combination of factors. We then obtained the average survival probabilities for each situation across data sets. 
The analysis was done using the statistical programming language $\mathrm{R}$, version 3.1.1, the ggplot2, rms and mice packages.

\section{RESULTS}

Characteristics of patients with 10 CLM or more compared to groups: 1-3 CLM and 4-9 CLM. As expected, the three groups (1-3 CLM, 4-9 CLM and $\geqslant 10$ CLM) exhibited major differences with regard to characteristics of patients, of primary tumour features, of metastatic disease and perioperative management. Comparisons are detailed in Table 1. Briefly, the number of CLM was associated with younger patients and lower proportion of rectal cancers. It also correlates with an increased maximal tumour size, an increased proportion of bilobar distribution, of synchronous CLM, of initial non-resectability and of preoperative chemotherapy. The proportion of $\mathrm{R} 2$ resection/no resection was the highest in the $\geqslant 10$ CLM group $(27.2 \%$ vs $14.7 \%$ and $5 \%$ in the 4-9 CLM group and 1-3 CLM group, respectively; $P<0.0001$ ).

Perioperative complications and mortality. The 90-day mortality observed in the $\geqslant 10$ CLM group was significantly higher $(4.8 \%)$. Severe morbidity (grade III-IV) was comparable to that of the 3-9 CLM group but higher than the group of 1-3 CLM. There was a significant increase in the risk of 90-day mortality with the age, for each subgroup of CLM number (Supplementary File 1).

Overall survival and disease-free survival. The median follow-up from diagnosis was 29.4 months. As expected, we observed a significant decrease in OS when comparing 1-3 CLM group vs 4-9 CLM group and 4-9 CLM group $v s \geqslant 10$ CLM group (Figure 1A). Accordingly, the 3- and 5-year OS rates were 70 and $49 \%$ in the
1-3 CLM group, 60 and 39\% in the 4-9 CLM group and 52 and $30 \%$ in the $\geqslant 10$ CLM group. Similar impact was observed for primary DFS (Figure 1B). Indeed, 3-year primary DFS was 38\%, $20 \%$ and $16 \%$ in patients with 1-3 CLM, 4-9 CLM and $\geqslant 10$ CLM, respectively $(P<0.0001)$.

Similar findings were observed when OS probabilities were calculated from the date of resection. The Kaplan-Meier OS curves are given in Supplementary File 2.

\section{Patients with $\geqslant 10$ CLM}

Proportion. Overall, the group $\geqslant 10$ CLM accounted for $4.3 \%$ of the entire study population. We observed a significant increase in the proportion of patients operated over the study period. The group $\geqslant 10$ CLM represented $3.8 \%$ of the cohort during the first part of the study period (January 2005-December 2008) vs $4.8 \%$ $(P=0.03)$ in the most recent period (January 2009-June 2013).

Resectability. Not surprisingly, the majority of patients (68.4\%) with 10 CLM or more received preoperative chemotherapy, and resection was undertaken after a control of the disease (response or stabilisation) in $96.3 \%$ of them.

The resectability $(\mathrm{R} 0 / \mathrm{R} 1)$ rate was $72.8 \%$. Among resected patients, the proportion of $\mathrm{R} 0$ resection and R1 resection (including use of local ablation) were $43.1 \%$ and $56.9 \%$, respectively.

Overall, $27.2 \%$ of patients with $\geqslant 10$ CLM underwent either (i) R2 resection: failure of planned two-stage hepatectomy $(N=62$, $48.1 \%$ ) or (ii) no resection at all because of intraoperative findings of unresectable CLM, and/or extrahepatic disease (lymph node, carcinomatosis $(N=67,51.9 \%))$.

Table 1. Baseline characteristics of each group

\begin{tabular}{|c|c|c|c|c|c|c|c|}
\hline \multirow[b]{2}{*}{ Variables } & \multicolumn{2}{|c|}{$1-3 \mathrm{CLM}$} & \multicolumn{2}{|c|}{ 4-9 CLM } & \multicolumn{2}{|c|}{$\geqslant 10 \mathrm{CLM}$} & \\
\hline & No. & $\%$ & No. & $\%$ & No. & $\%$ & $P$ \\
\hline Sex: male & 5932 & 61.5 & 1400 & 62.7 & 315 & 59.5 & 0.36 \\
\hline Mean age ( \pm s.d.), years & \multicolumn{2}{|c|}{$63.3( \pm 11)$} & \multicolumn{2}{|c|}{$60.1( \pm 11)$} & \multicolumn{2}{|c|}{$58.5( \pm 10)$} & $<0.0001$ \\
\hline \multicolumn{8}{|l|}{ Primary tumour } \\
\hline \multicolumn{8}{|l|}{ CLM characteristics } \\
\hline Mean number of CLM ( \pm s.d.) & \multirow{3}{*}{\multicolumn{2}{|c|}{$\begin{array}{c}1.6( \pm 0.7) \\
37.6( \pm 28) \\
119.4( \pm 80)\end{array}$}} & \multirow{3}{*}{\multicolumn{2}{|c|}{$\begin{array}{c}5.3( \pm 1.4) \\
38.9( \pm 28) \\
123.4( \pm 79)\end{array}$}} & \multirow{3}{*}{\multicolumn{2}{|c|}{$\begin{array}{c}13.4( \pm 4) \\
44.5( \pm 35) \\
137.1( \pm 77)\end{array}$}} & $<0.0001$ \\
\hline Mean maximum tumour size $( \pm \mathrm{s} . \mathrm{d}),. \mathrm{mm}$ & & & & & & & $<0.0001$ \\
\hline Mean CEA level, $\mathrm{ng} \mathrm{ml}^{-1}$ & & & & & & & $<0.0001$ \\
\hline Distribution: bilobar & 2141 & 22.4 & 1736 & 78.6 & 497 & 94.3 & $<0.0001$ \\
\hline Initially resectable & 7774 & 88.2 & 1283 & 62.6 & 163 & 32.1 & $<0.0001$ \\
\hline Preop. chemotherapy & 3391 & 37.1 & 1329 & 61.9 & 353 & 68.4 & $<0.0001$ \\
\hline Preop. targeted therapy & 1277 & 38.6 & 629 & 47.9 & 208 & 59.3 & $<0.0001$ \\
\hline Progression while on chemotherapy ${ }^{a}$ & 261 & 7.7 & 83 & 6.2 & 13 & 3.7 & 0.002 \\
\hline Portal vein embolisation & 561 & 6.1 & 424 & 19.5 & 201 & 39.1 & $<0.0001$ \\
\hline Postop. chemotherapy & 3824 & 54.2 & 963 & 56.4 & 191 & 51.3 & 0.12 \\
\hline Postop. targeted therapy & 752 & 20.3 & 309 & 32.7 & 83 & 43.9 & $<0.0001$ \\
\hline \multicolumn{8}{|l|}{ Early outcomes } \\
\hline RO/R1 liver resection & 8742 & 95.0 & 1790 & 85.3 & 346 & 72.8 & $<0.0001$ \\
\hline 90-day mortality & 200 & 2.1 & 76 & 3.4 & 25 & 4.8 & 0.0001 \\
\hline Grade III-IV morbidity ${ }^{b}$ & 1389 & 16.8 & 363 & 19.0 & 81 & 18.7 & 0.05 \\
\hline
\end{tabular}




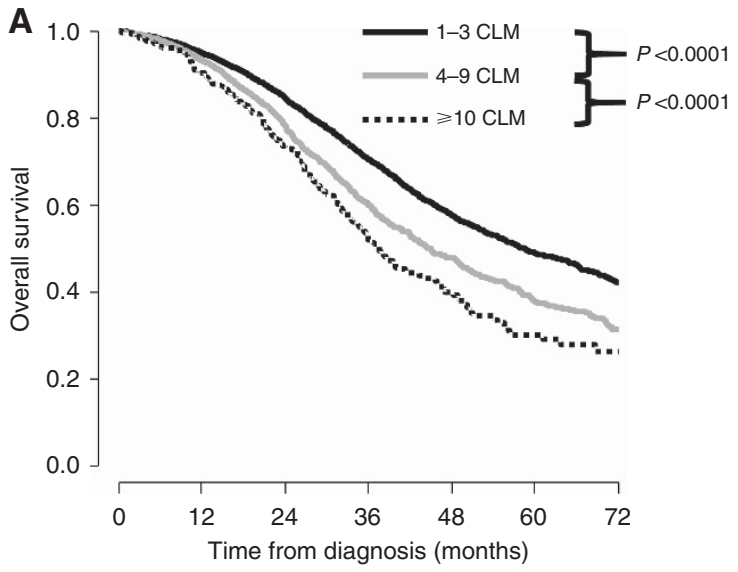

$\begin{array}{lrrrrrrrr}\text { No. at risk } & 9643 & 7107 & 4718 & 2870 & 1613 & 874 & 416 & 1-3 \text { CLM } \\ & 2234 & 1700 & 1077 & 568 & 296 & 138 & 71 & 4-9 \text { CLM } \\ & 529 & 385 & 230 & 120 & 59 & 28 & 14 & \geqslant 10 \text { CLM }\end{array}$

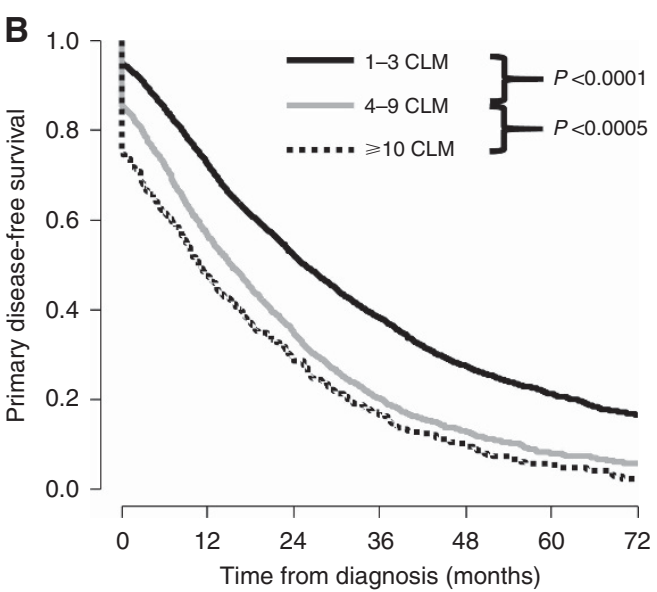

\begin{tabular}{|c|c|c|c|c|c|c|c|}
\hline No. at risk & 96435171 & 3018 & 1788 & 960 & 507 & 235 & 1-3 CLM \\
\hline & 22341002 & 545 & 263 & 142 & 70 & 34 & $4-9 \mathrm{CL}$ \\
\hline & $529 \quad 208$ & 116 & 59 & 31 & 14 & 5 & $\geqslant 100$ \\
\hline
\end{tabular}

Figure 1. Survival according to the number of CLM. (A) KaplanMeier overall survival curves according to the number of CLM. (B) Kaplan-Meier primary disease-free survival according to the number of CLM.

\section{Identification of the prognostic factors for OS in patients with $\geqslant 10$ CLM}

Univariate analysis. We did not observe any difference in terms of OS between R0 patients and R1/combined RFA patients (3- and 5 -year OS rates of 73 and $45 \%$ vs 60 and $44 \%$; $P=0.72$ ). Patients with R2 resection achieved similar outcomes than those without any resection (3- and 5-year OS rates of 29 and $6 \%$ vs 28 and $0 \%$ for $\mathrm{R} 2$ resection and no resection group; $P=0.77$ ). However, the 3 and 5-year OS rates were much higher for combined R0/R1 resection groups compared to R2/no resection groups (61 and 39\% for R0/R1 resection group vs 29 and $5 \%$ in the group with $\mathrm{R} 2 /$ no resection at 3 and 5 years, respectively, $P<0.0001$; Figure $2 \mathrm{~A}$ ). Then, we decided to perform the analysis by combining R0/R1 resection and $\mathrm{R} 2 /$ no resection groups.

Results of univariate analysis in original set and imputed data are provided in Table 2 . Others factors with a $P$-value $<0.15$ were as follows: age $\geqslant 60$ years; maximal tumour size $\geqslant 40 \mathrm{~mm}$; a preoperative MRI; preoperative chemotherapy; and adjuvant chemotherapy. Of note, the number of CLM in the group of
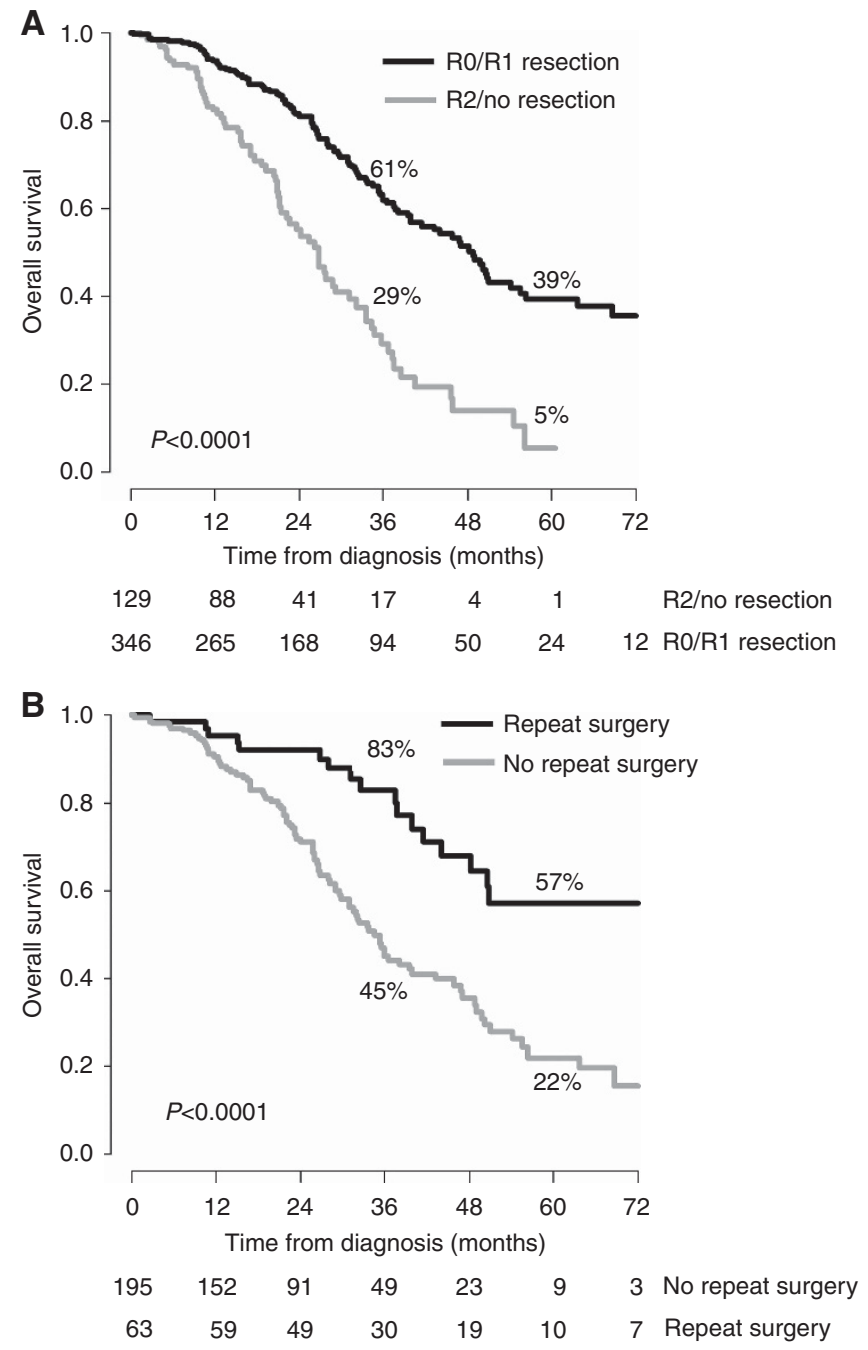

Figure 2. Survival according to the quality of resection and the possibility of repeat resection. (A) Kaplan-Meier overall survival curves according to the R0/R1 resection possibility. (B) Kaplan-Meier overall survival curves of patients who relapsed after R1/R0 resection according to the use of repeat surgery.

patients with $\geqslant 10$ CLM had no influence on outcome (HR: 1.0 (0.97-1.03); $P=0.92)$.

Multivariate analysis. The five factors that remained in the Cox model in all data sets were the following: type of resection (R0/R1); age $\geqslant 60$ years; adjuvant chemotherapy; maximal tumour size $\geqslant 40 \mathrm{~mm}$; and preoperative MRI. The $C$-index ranged from 0.68 to 0.71 across imputed data sets.

The pooled estimates of the factors, retained in the final model, are as follows: R0/R1 resection (HR $0.35(0.26-0.48) ; P<0.0001$ ); preoperative MRI (HR 0.65 (0.47-0.89); $P=0.007$ ); adjuvant chemotherapy (HR $0.73(0.55-0.98) ; P=0.04)$; maximal tumour size $\geqslant 40 \mathrm{~mm}$ (HR $1.49(1.09-2.03) ; P=0.02)$; and age $\geqslant 60$ years (HR 1.51 (1.13-2.00), $P=0.005$; Table 3).

Recurrence after R0/R1 liver resection. The primary DFS was similar between the group R0 resection and that with R1 resection/ RFA use (31 and $8 \%$ vs 22 and $6 \%$ at 3 and 5 years; $P=0.56$ ).

Of the 346 patients who underwent R0/R1 resection, 258 (74.6\%) had developed a recurrence at last follow-up. The 3- and 5year primary DFS rates were $23 \%$ and $7 \%$, respectively. Hepatic recurrence and extrahepatic recurrence were surgically treated in 49 (19\%) and 14 patients (5.4\%), respectively. The secondary DFS 
Table 2. Univariate analysis for overall survival in patients with $\geqslant 10$ CLM (original data set)

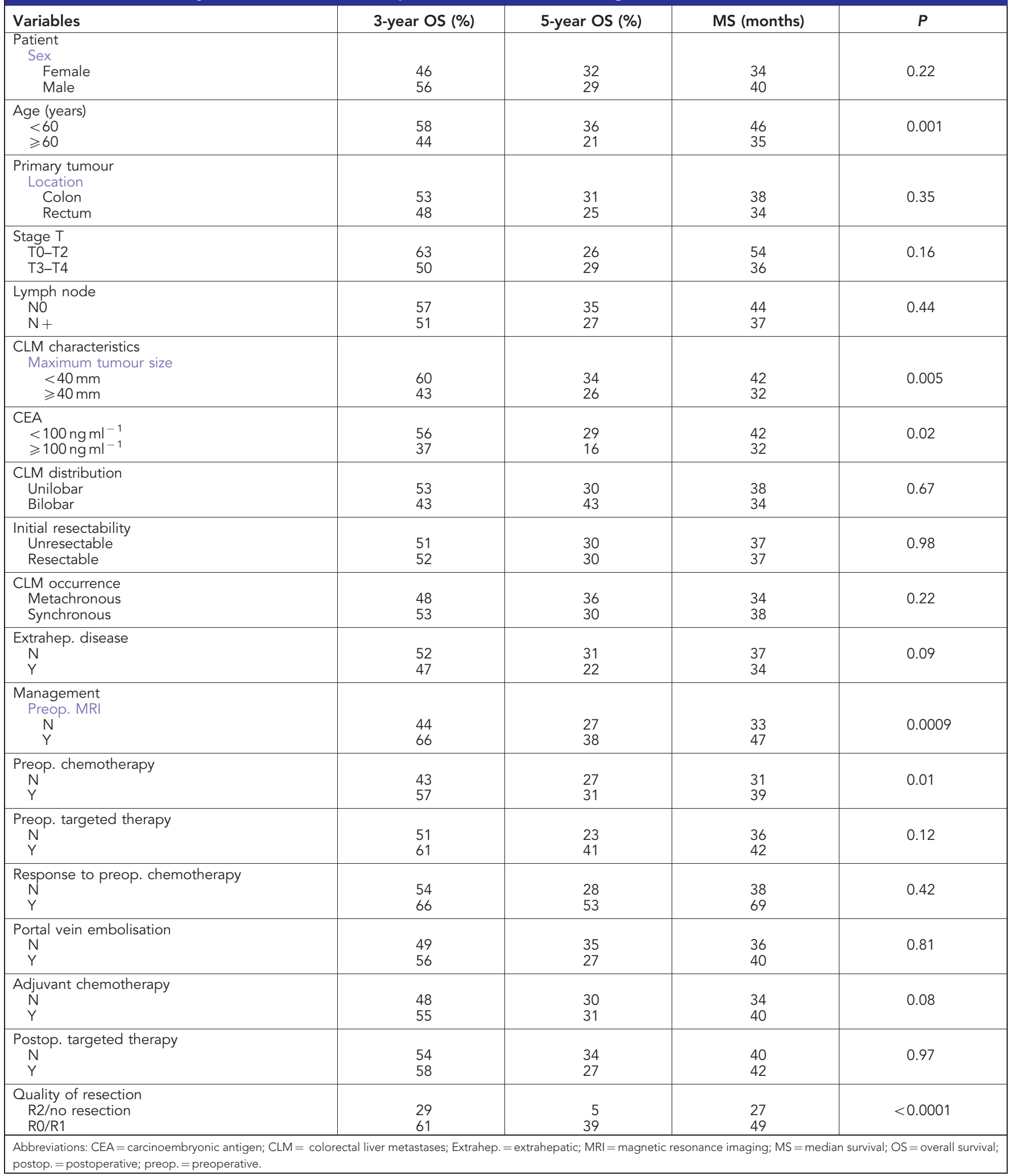

rates (taking into account the impact of repeat surgery) at 3 and 5 years were $42 \%$ and $31 \%$, respectively. The OS of patients who underwent repeat surgery was significantly better than that of patients whom recurrence was managed by exclusive chemotherapy (83 and $57 \%$ vs 45 and $22 \%$ at 3 and 5 years; $P<0.0001$; Figure 2B).
Survival probabilities according to the distribution of prognostic factors. We calculated the average survival probabilities across imputed data sets in patients who underwent R0/R1 resection according to each cofactor association (Table 4).

Thus, patients with all additional four favourable factors, the 3and 5-year OS rates were $82 \%$ and $69 \%$, respectively. The OS 
probability at 3 and 5 years decreased to $70-77 \%$ and $50-61 \%$ in patients with three additional favourable factors, 58-68\% and 35$47 \%$ in patients with two additional favourable factors, $44-55 \%$ and $21-32 \%$ in patients with one additional factor, and 33 and $12 \%$ in patients with no additional positive factors (Table 4).

\section{DISCUSSION}

General considerations. The main finding of the current study is that a 5-year OS and median survival of at least of $21 \%$ and 34 months can be achieved in patients with $\geqslant 10$ CLM after complete treatment of macroscopic liver disease in patients with at least a single additional favourable factor: age $<60$ years; a maximal tumour size $<40 \mathrm{~mm}$; preoperative MRI; preoperative chemotherapy; and adjuvant chemotherapy.

Although 10 liver metastases or more is a common presentation at diagnosis, the low proportion of this group reported here $(4.3 \%$ of the cohort) indicates that (1) most centres consider such number of CLM as a contraindication for resection and (2) patients operated are highly selected. This also translates the fact that an important number of CLM may compromise technical feasibility of complete resection. Indeed, the proportion of patients with $\geqslant 10$ CLM, finally unresected or with incomplete resection $(27.2 \%)$ demonstrates how challenging it is to achieve curative resection in these patients

Table 3. Pooled estimates of multivariate analysis for overall survival in patients with $\geqslant 10 \mathrm{CLM}$

\begin{tabular}{|c|c|c|c|c|}
\hline Variables & HR & Lower $\mathrm{Cl}$ & Upper Cl & $P$ \\
\hline Max tumour size $\geqslant 40 \mathrm{~mm}$ & 1.49 & 1.09 & 2.03 & 0.02 \\
\hline Age $\geqslant 60$ years & 1.51 & 1.13 & 2.00 & 0.005 \\
\hline Preoperative MRI & 0.65 & 0.47 & 0.89 & 0.007 \\
\hline $\mathrm{R} 0 / \mathrm{R} 1$ resection & 0.35 & 0.26 & 0.48 & $<0.0001$ \\
\hline Adjuvant chemotherapy & 0.73 & 0.55 & 0.98 & 0.04 \\
\hline
\end{tabular}

Preoperative chemotherapy. Resection in patients with disease progression while on chemotherapy was anecdotal (3.7\%). This is in accordance with previous studies showing the importance of a disease control before considering surgery in patients with advanced liver disease (Adam et al, 2004a, b; Garufi et al, 2010). Therefore, the present findings cannot be applied in patients with a progressive metastatic disease. The interpretation of our results should be made at the light of this prerequisite.

What are the conditions that may ensure an additional benefit of surgery compared to chemotherapy alone?. Interestingly, the median survival of patients with $\mathrm{R} 2 /$ no resection ( 27 months) was similar to that reported in contemporary trials of chemotherapies in patients with metastatic unresectable disease (Heinemann et al, 2014; Loupakis et al, 2014), whereas the survival of R0/R1 patients (median survival 49 months) was by far better and close to survival rates observed in resected patients with fewer CLM (Nordlinger et al, 2013). This shows that even in patients with very advanced disease, resection has the potential to improve patient outcome.

Interestingly, preoperative MRI emerged as a favourable prognostic factor, independently of the other 'oncological' parameters. Given the superiority of MRI over CT scan for detecting small nodules, especially after neoadjuvant chemotherapy (Kulemann et al, 2011), a shift in the disease staging may be advanced to explain this finding. Indeed, it is likely that some patients, initially considered as 'resectable' based on CT scan, may become ineligible for surgery after preoperative MRI. This results in a more favourable tumour biology or less-advanced disease in the subgroup of patients with preoperative MRI. We also may hypothesised that the quality of resection, especially in patients at high risk of very small tumour foci, such as the ones with $\geqslant 10$ CLM may be improved after MRI.

According to our multivariate model, macroscopically complete resection, alone (i.e., without additional favourable factors), is associated with a median OS of 31 months and a 12\% 5-year OS. The addition of a single favourable factor to R0/R1 surgery was associated with a 5 -year OS of $21-32 \%$ and a MS of $34-42$ months. This suggests that surgical treatment (often complex and potentially morbid given the extent of the liver disease) should

Table 4. Survival probabilities according to prognostic factors combinations in patients with $\geqslant 10$ CLM who underwent RO/R1 resection

\begin{tabular}{|c|c|c|c|c|c|c|c|}
\hline $\begin{array}{l}\text { R0/R1 } \\
\text { resection }\end{array}$ & $\begin{array}{l}\text { Preop. } \\
\text { MRI }\end{array}$ & $\begin{array}{l}\text { Maximum tumour size } \\
<40 \mathrm{~mm}\end{array}$ & $\begin{array}{c}\text { Age }<60 \\
\text { years }\end{array}$ & $\begin{array}{c}\text { Adjuvant } \\
\text { chemotherapy }\end{array}$ & $\begin{array}{c}3-y r \text { OS } \\
(\%)\end{array}$ & $\begin{array}{c}\text { 5-yr OS } \\
(\%)\end{array}$ & $\begin{array}{c}\text { MS } \\
\text { (months) }\end{array}$ \\
\hline+ & + & + & + & + & 82 & 69 & NR \\
\hline+ & - & + & + & + & 74 & 57 & NR \\
\hline+ & + & - & + & + & 70 & 50 & 69 \\
\hline+ & + & + & - & + & 77 & 61 & NR \\
\hline+ & + & + & + & - & 75 & 57 & NR \\
\hline+ & + & - & + & - & 58 & 36 & 47 \\
\hline+ & + & - & - & + & 62 & 40 & 50 \\
\hline+ & - & - & + & + & 58 & 35 & 47 \\
\hline+ & - & + & - & + & 67 & 47 & 54 \\
\hline+ & - & + & + & - & 64 & 43 & 51 \\
\hline+ & - & - & - & + & 48 & 25 & 36 \\
\hline+ & - & - & - & - & 33 & 12 & 31 \\
\hline
\end{tabular}


be undertaken only in patients with at least a single additional favourable factor.

Outcomes of patients with $\geqslant 10$ CLM are hampered by a high rate of relapse $(74.6 \%)$. This argues in favour of routine postoperative chemotherapy, an independent factor of improved OS. Improvement in adjuvant therapy may warrant more favourable results in this subgroup of patients at high risk of recurrence and then should be further investigated. In this setting, hepatic arterial infusion may be a valid option to control microscopic residual disease as recently suggested. (Goéré et al, 2013). However, contrary to randomised studies, the design of the present study did not allow to demonstrate the favourable impact of adjuvant therapy on survival. As most of institutions would refer patients with $\geqslant 10$ CLM for adjuvant therapy, it is likely that the absence of post-operative chemotherapy is likely to be due to adverse postoperative events such as surgical complications or deterioration of the general status.

Repeat hepatectomy or extrahepatic resection for patients with recurrence is another way to improve the outcome of these patients as demonstrated by the better survival of patients submitted to this repeat surgery, compared to those submitted to a single surgical procedure. Of course, this group consists of selected patients, with favourable tumour biology. However, these good outcomes emphasise the relevance of an aggressive onco-surgical approach.

R0/R1 resection. Here we grouped R0/R1 resection. This may be surprising knowing that $\mathrm{R} 0$ resection must remain an oncological goal in surgery of CLM. However, in patients with $\geqslant 10$ CLM, R0 and $\mathrm{R} 1$ resection yield similar survival as this has been already reported in patients with a large number of CLM (de Haas et al, 2008; Folprecht et al, 2014). The proportion of R1 resection directly results of the high number of lesions, the frequent use of RFA and the necessity to preserve vascular structures.

At least 10 CLM on imaging studies obviously represents an advanced stage of the metastatic disease and it is likely that many small tumour foci cannot be detected by imaging studies. Therefore, the survival benefit offered by a macroscopically complete surgery that cannot eradicate all microscopic tumours of the liver questions in some extent the 'only R0' principle of oncologic surgery. These so-called 'macroscopically complete resections' could in fact be likened from an oncological point of view to cytoreductive surgery advocated in ovarian cancers whose prognosis correlates with tumour residual (Winter et al, 2008).

Limitations of the study. This analysis carries some limitations. The study is retrospective, multicentric and as a result, may suffer from different selection criteria and heterogeneity in patient management (preoperative imaging studies and experience in complex liver surgery) between centres. We acknowledge that patients with at least 10 CLM represents a highly selected population. For that reason, we cannot ascertain that similar results may be observed in a less selected cohort. It would also have been interesting to precisely investigate the impact of the overall tumour burden but this would imply an accurate information of all tumour foci (for example, the tumour size of all metastases at all locations). Such data are not available in the registry. Unfortunately, the impact of preoperative PET-CT, already emphasised (Wiering et al, 2005), could not be evaluated due to lacking data. However, these results offer the advantage to reflect the 'true life' of resection in this setting, irrespective of the level of expertise of the centre. Moreover, these results represent the largest series reported to date of patients with such a number of CLM.

In conclusion, the long-term outcome of patients with 10 CLM or more is obviously worse compared to patients exhibiting fewer lesions, but surgery after effective chemotherapy remains the only hope of prolonged survival, especially in selected patients for whom complete resection could be performed. In fact, it is likely that the ' 10 and more' patients only represent the visible part of the iceberg. The present results show that the number of CLM should not be considered as contraindication to surgery per se and should encourage oncologists and surgeons to extend the surgical indications beyond commonly admitted boundaries.

\section{ACKNOWLEDGEMENTS}

We thank all centres contributing to LiverMetSurvey and Valérie Delvart for performing the statistical analysis of this study. There is no financial support for the study. LiverMetSurvey is supported by a grant from Sanofi-Aventis.

\section{CONFLICT OF INTEREST}

The authors declare no conflict of interest.

\section{AUTHOR CONTRIBUTIONS}

Conceptualisation and methodology: MAA and RA; formal analysis: MAA and RA; writing and manuscript preparation: MAA and RA; review and editing: FG, RL, CH, JNMI, DFM, DE, CL, TG, GP, CL, HI, JH, VL, IP and JF.

\section{REFERENCES}

Adam R, Bhangui P, Poston G, Mirza D, Nuzzo G, Barroso E, Ijzermans J, Hubert C, Ruers T, Capussotti L, Ouellet J-F, Laurent C, Cugat E, Colombo PE, Milicevic M (2010) Is perioperative chemotherapy useful for solitary, metachronous, colorectal liver metastases? Ann Surg 252: 774-787.

Adam R, De Gramont A, Figueras J, Guthrie A, Kokudo N, Kunstlinger F, Loyer E, Poston G, Rougier P, Rubbia-Brandt L, Sobrero A, Tabernero J, Teh C, Van Cutsem E (2012) The oncosurgery approach to managing liver metastases from colorectal cancer: a multidisciplinary international consensus. Oncologist 17: 1225-1239.

Adam R, Delvart V, Pascal G, Valeanu A, Castaing D, Azoulay D, Giacchetti S, Paule B, Kunstlinger F, Gh??mard O, Levi F, Bismuth H (2004a) Rescue surgery for unresectable colorectal liver metastases downstaged by chemotherapy. Ann Surg 240: 644-657.

Adam R, Pascal G, Castaing D, Azoulay D, Delvart V, Paule B, Levi F, Bismuth H (2004b) Tumor progression while on chemotherapy. Ann Surg 240: $1052-1064$.

Adam R, Wicherts DA, de Haas RJ, Ciacio O, Levi F, Paule B, Ducreux M, Azoulay D, Bismuth H, Castaing D (2009) Patients with initially unresectable colorectal liver metastases: is there a possibility of cure? J Clin Oncol 27: 1829-1835.

Andres A, Toso C, Adam R, Barroso E, Hubert C, Capussotti L, Gerstel E, Roth A, Majno PE, Mentha G (2012) A survival analysis of the liver-first reversed management of advanced simultaneous colorectal liver metastases. Ann Surg 256: 772-779.

Cremolini C, Loupakis F, Antoniotti C, Lupi C, Sensi E, Lonardi S, Mezi S, Tomasello G, Ronzoni M, Zaniboni A, Tonini G, Carlomagno C, Allegrini G, Chiara S, D’Amico M, Granetto C, Cazzaniga M, Boni L, Fontanini G, Falcone A (2015) FOLFOXIRI plus bevacizumab versus FOLFIRI plus bevacizumab as first-line treatment of patients with metastatic colorectal cancer: updated overall survival and molecular subgroup analyses of the open-label, phase 3 TRIBE study. Lancet Oncol 16: 1306-1315.

Cutsem V, Köhne CH, Hitre E, Zaluski J, Chang Chien C-R, Makhson A, D’Haens G, Pintér T, Lim R, Bodoky G, Roh JK, Folprecht G, Ruff P, Stroh C, Tejpar S, Schlichting M, Nippgen J, Rougier P (2009) Cetuximab and chemotherapy as initial treatment for metastatic colorectal cancer. $N$ Engl J Med 360: 1408-1417.

de Haas RJ, Wicherts DA, Flores E, Azoulay D, Castaing D, Adam R (2008) R1 resection by necessity for colorectal liver metastases. Trans Meet Am Surg Assoc 126: 269-280. 
Ekberg H, Tranberg KG, Andersson R, Lundstedt C, Hägerstrand I, Ranstam J, Bengmark S (1986) Determinants of survival in liver resection for colorectal secondaries. Br J Surg 73: 727-731.

Elias D, Liberale G, Vernerey D, Pocard M, Ducreux M, Boige V, Malka D, Pignon J-P, Lasser P (2005) Hepatic and extrahepatic colorectal metastases: when resectable, their localization does not matter, but their total number has a prognostic effect. Ann Surg Oncol 12: 900-909.

Ferrero A, Polastri R, Muratore A, Zorzi D, Capussotti L (2004) Extensive resections for colorectal liver metastases. J Hepatobiliary Pancreat Surg 11: 92-96.

Folprecht G, Gruenberger T, Bechstein W, Raab H-R, Weitz J, Lordick F, Hartmann JT, Stoehlmacher-Williams J, Lang H, Trarbach T, Liersch T, Ockert D, Jaeger D, Steger U, Suedhoff T, Rentsch A, Köhne C-H (2014) Survival of patients with initially unresectable colorectal liver metastases treated with FOLFOX/cetuximab or FOLFIRI/cetuximab in a multidisciplinary concept (CELIM study). Ann Oncol 25: 1018-1025.

Garufi C, Torsello A, Tumolo S, Ettorre GM, Zeuli M, Campanella C, Vennarecci G, Mottolese M, Sperduti I, Cognetti F (2010) Cetuximab plus chronomodulated irinotecan, 5-fluorouracil, leucovorin and oxaliplatin as neoadjuvant chemotherapy in colorectal liver metastases: POCHER trial. Br J Cancer 103: 1542-1547.

Goéré D, Benhaim L, Bonnet S, Malka D, Faron M, Elias D, Lefèvre JH, Deschamps F, Dromain C, Boige V, Dumont F, De Baere T, Ducreux M (2013) Adjuvant chemotherapy after resection of colorectal liver metastases in patients at high risk of hepatic recurrence: a comparative study between hepatic arterial infusion of oxaliplatin and modern systemic chemotherapy. Ann Surg 257: 114-120.

Heinemann V, von Weikersthal LF, Decker T, Kiani A, Vehling-Kaiser U, Al-Batran S-E, Heintges T, Lerchenmüller C, Kahl C, Seipelt G, Kullmann F, Stauch M, Scheithauer W, Hielscher J, Scholz M, Müller S, Link H, Niederle N, Rost A, Höffkes H-G, Moehler M, Lindig RU, Modest DP, Rossius L, Kirchner T, Jung A, Stintzing S (2014) FOLFIRI plus cetuximab versus FOLFIRI plus bevacizumab as first-line treatment for patients with metastatic colorectal cancer (FIRE-3): a randomised, open-label, phase 3 trial. Lancet Oncol 15(10): 1065-1075.

Janssen KJM, Donders ART, Harrell FE, Vergouwe Y, Chen Q, Grobbee DE, Moons KGM (2010) Missing covariate data in medical research: to impute is better than to ignore. J Clin Epidemiol 63: 721-727.

Kabbinavar FF, Hurwitz HI, Yi J, Sarkar S, Rosen O (2009) Addition of bevacizumab to fluorouracil-based first-line treatment of metastatic colorectal cancer: pooled analysis of cohorts of older patients from two randomized clinical trials. J Clin Oncol 27: 199-205.

Kulemann V, Schima W, Tamandl D, Kaczirek K, Gruenberger T, Wrba F, Weber M, Ba-Ssalamah A (2011) Preoperative detection of colorectal liver metastases in fatty liver: MDCT or MRI? Eur J Radiol 79: 1-6.

Loupakis F, Cremolini C, Masi G, Lonardi S, Zagonel V, Salvatore L, Cortesi E, Tomasello G, Ronzoni M, Spadi R, Zaniboni A, Tonini G, Buonadonna A, Amoroso D, Chiara S, Carlomagno C, Boni C, Allegrini G, Boni L, Falcone A (2014) Initial therapy with FOLFOXIRI and bevacizumab for metastatic colorectal cancer. N Engl J Med 371: 1609-1618.

Nordlinger B, Sorbye H, Glimelius B, Poston GJ, Schlag PM, Rougier P, Bechstein WO, Primrose JN, Walpole ET, Finch-Jones M, Jaeck D, Mirza D, Parks RW, Mauer M, Tanis E, Van Cutsem E, Scheithauer W,
Gruenberger T (2013) Perioperative FOLFOX4 chemotherapy and surgery versus surgery alone for resectable liver metastases from colorectal cancer (EORTC 40983): long-term results of a randomised, controlled, phase 3 trial. Lancet Oncol 14: 1208-1215.

Rees M, Tekkis PP, Welsh FKS, O'Rourke T, John TG (2008) Evaluation of long-term survival after hepatic resection for metastatic colorectal cancer: a multifactorial model of 929 patients. Ann Surg 247: 125-135.

Rubin DB (1987) Multiple imputation for nonresponse in surveys. John Wiley \& Sons: New York, NY, USA.

Smith MD, McCall JL (2009) Systematic review of tumour number and outcome after radical treatment of colorectal liver metastases. Br J Surg 96: 1101-1113.

Tamandl D, Gruenberger B, Herberger B, Schoppmann S, Bodingbauer M, Schindl M, Puhalla H, Fleischmann E, Schima W, Jakesz R, Laengle F, Gruenberger T (2007) Selective resection of colorectal liver metastases. Eur J Surg Oncol 33: 174-182.

Van Cutsem E, Köhne C-H, Láng I, Folprecht G, Nowacki MP, Cascinu S, Shchepotin I, Maurel J, Cunningham D, Tejpar S, Schlichting M, Zubel A, Celik I, Rougier P, Ciardiello F (2011) Cetuximab plus irinotecan, fluorouracil, and leucovorin as first-line treatment for metastatic colorectal cancer: updated analysis of overall survival according to tumor KRAS and BRAF mutation status. J Clin Oncol 29: 2011-2019.

Viganò L, Capussotti L, Barroso E, Nuzzo G, Laurent C, Ijzermans JNM, Gigot J-F, Figueras J, Gruenberger T, Mirza DF, Elias D, Poston G, Letoublon C, Isoniemi H, Herrera J, Sousa FC, Pardo F, Lucidi V, Popescu I, Adam R (2012) Progression while receiving preoperative chemotherapy should not be an absolute contraindication to liver resection for colorectal metastases. Ann Surg Oncol 19: 2786-2796.

Viganò L, Capussotti L, Majno P, Toso C, Ferrero A, De Rosa G, Rubbia-Brandt L, Mentha G (2015) Liver resection in patients with eight or more colorectal liver metastases. Br J Surg 102: 92-101.

Wiering B, Krabbe PFM, Jager GJ, Oyen WJG, Ruers TJM (2005) The impact of fluor-18-deoxyglucose-positron emission tomography in the management of colorectal liver metastases: a systematic review and metaanalysis. Cancer 104: 2658-2670.

Wilson SM, Adson MA (1976) Surgical treatment of hepatic metastases from colorectal cancers. Arch Surg 111: 330-334.

Winter WE, Maxwell GL, Tian C, Sundborg MJ, Rose GS, Rose PG, Rubin SC, Muggia F, McGuire WP (2008) Tumor residual after surgical cytoreduction in prediction of clinical outcome in stage IV epithelial ovarian cancer: a Gynecologic Oncology Group Study. J Clin Oncol 26: 83-89.

Zakaria S, Donohue JH, Que FG, Farnell MB, Schleck CD, Ilstrup DM, Nagorney DM (2007) Hepatic resection for colorectal metastases: value for risk scoring systems? Ann Surg 246: 183-191.

This work is published under the standard license to publish agreement. After 12 months the work will become freely available and the license terms will switch to a Creative Commons AttributionNonCommercial-Share Alike 4.0 Unported License.

Supplementary Information accompanies this paper on British Journal of Cancer website (http://www.nature.com/bjc) 